\title{
Role Of Implants In Orthodontics
}

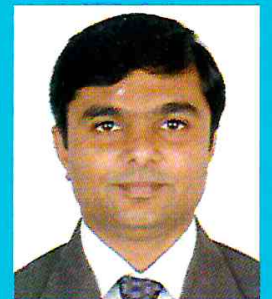

Dr. Naveen Shamanur Professor

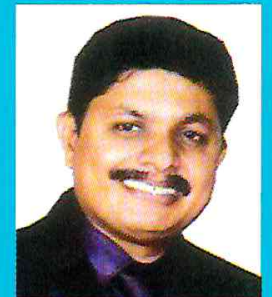

Dr. Arun Kumar . G Professor

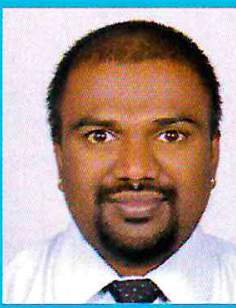

Dr. Gopalkrishna B.R Asst. Professor

\section{Department Of Orthodontics}

\section{INTRODUCTION :}

Orthodontics has undergone a sea change in the last few years but until recently, the speciality has not felt the impact that other areas of dentistry have witnessed as a result of implantology.

The use of implants in dentistry began when Branemark et al published the success of osseo-integrated titanium endosseous implants.

Use of dental implants has greatly increased over the last three decades, largely as a consequence of their successful long term osseo-integration. This has led to increased orthodontic use, with appropriate modifications where required.

Implants can offer an option when replacing missing teeth, following orthodontic treatment. Use of implants during orthodontic treatment are ${ }^{1}$ :

\section{Implants as a source of absolute anchorage}

Implants as anchorage and later as abutments for restorarions.

$>$ Implants in osteogenic distraction.

$>$ Implant site preparation improved by orthodontics.

According to Branemark's "Osseointegration is the structural and functional connection between ordered living bone and the surface of a load carrying implant,"

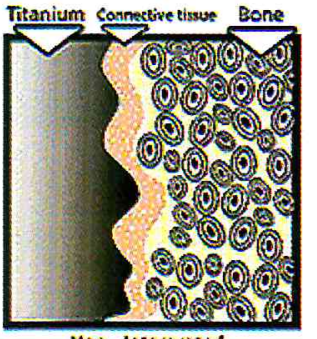

Non - Intergrated

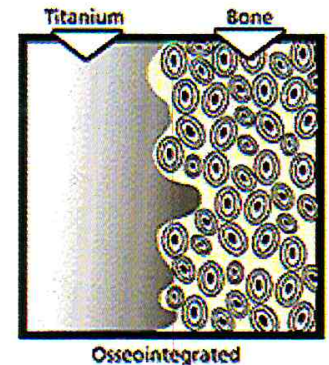

The materials used for implants can be broadly divided into 3 categories $^{2}:-$

1. Biotolerant: - Material that is not necessarily rejected but is surrounded by fibrous layer in the form of a capsule. Eg. Stainless Steel, Chromium-Cobalt Alloy.

2. Bioinert: - Material that allows close apposition of bone on their surface, leading to contact osteogenesis. Eg. Titanium, Carbon.

3. Bioactive: - Materials that allow formation of new bone onto their surface, but ion exchange with host tissue leads to formation of a chemical bond along the interface (bonding osteogenesis). Eg. Vetro ceramic apatite hydroxide, Ceramic oxidized aluminum.

\section{Classification of implants}

Dental implants can be classified on the basis of the following criteria ${ }^{2}$ :

1. According to location

2. According to configuration

3. According to composition

4. According to surface structure

1. According to location

i. Subperiosteal Implants: In this design the implant body lies over the bony ridge. This type of design currently in use for orthodontic purposes is the 'Onplant'.

ii. Transosseous Implants: In this type, the implant penetrates the bone completely. This design is not widely used either in restorative dentistry or orthodontics. 
iii. Endosseous Implants: These implants are partially submerged and anchored within the bone. These have been the most popular and the widely used ones. Various designs and compositions are available for usage in specific conditions.

iv. Endodontic Stabilizers

v. Intra-mucosal Inserts

vi. Bone Augmentation Materials

\section{According to Configuration}

i. Root Form Implants: These are the screw type endosseous implants and the name has been derived due to their cylindrical structure.

a. Press Fit (unthreaded but covered with hydroxyapatite spray)

b. Self Tapping (threaded)

c. Pre Tapping (threaded)

ii. Blade/Plate Form Implants: These are flatter and can be used in resorbed and knife edge ridges
a. PreFabricated
b. Custom Cast
c. Alterable (by bending, cutting, shaping)

\section{According to composition}

\section{i. Stainless Steel}

ii. Cobalt-Chromium-Molybdenum

iii. Titanium

iv. Ceramic Implants

v. Miscellaneous such as Vitreous Carbon and Composites

\section{According to the surface structure}

i. Threaded or Non-threaded : The root form implants are generally threaded, as this provides for a greater surface area and stability of the implant.

ii. Porous or Non-Porous : The screw type implants are usually non-porous whereas the plate or blade implants have vents in the implant body to aid in ingrowth of bone and thus a better interlocking between the metal structure and the surrounding bone.

The anchorage derived from implants is categorized into

i) Direct Anchorage: in which and endosseous implant is used as an anchorage site as in prosthetic rehabilitation.

ii) Indirect Anchorage: where the purpose of the implant is to preserve the anchorage

Advantages of mini-implant anchorage ${ }^{3,4,5}$ :

\begin{tabular}{|c|c|}
\hline APPLICATION & ADVANTAGE \\
\hline $\begin{array}{l}\text { Intrude / } \\
\text { Extrude Teeth }\end{array}$ & $\begin{array}{l}\text { - Reduce complications } \\
\text { and facilitate movement } \\
\text { - Mini-implants more } \\
\text { feasible than conventional } \\
\text { ones }\end{array}$ \\
\hline $\begin{array}{l}\text { Close } \\
\text { Edentulous Spaces }\end{array}$ & $\begin{array}{l}\text { - Avoid the need for a } \\
\text { prosthesis } \\
\text { - Reduce endodontic } \\
\text { complications } \\
\text { - Enhance oral hygiene }\end{array}$ \\
\hline $\begin{array}{l}\text { Reposition } \\
\text { Malposed Teeth }\end{array}$ & $\begin{array}{l}\text { Improve anchorage } \\
\text { Reconstruct the edentulous } \\
\text { area }\end{array}$ \\
\hline Reinforce Anchorage & $\begin{array}{l}\text { - Maximize anchorage } \\
\text { - Improve patient compliance } \\
\text { (No headgear, Class II } \\
\text { elastics) }\end{array}$ \\
\hline Partial Edentulism & $\begin{array}{l}\text { - Future restorative abutments } \\
\text { - Reduce Dental } \\
\text { complications }\end{array}$ \\
\hline $\begin{array}{l}\text { Correct Undesirable } \\
\text { Occlusion }\end{array}$ & $\begin{array}{l}\text { - Provide solid anchorage to } \\
\text { retract entire arch } \\
\text { - Facilitate localized } \\
\text { bonding and treatment }\end{array}$ \\
\hline $\begin{array}{l}\text { Orthopedic } \\
\text { Movement }\end{array}$ & $\begin{array}{l}\text { - Accelerate sutural } \\
\text { distraction (palatal } \\
\text { expansion) and bone } \\
\text { movement }\end{array}$ \\
\hline
\end{tabular}



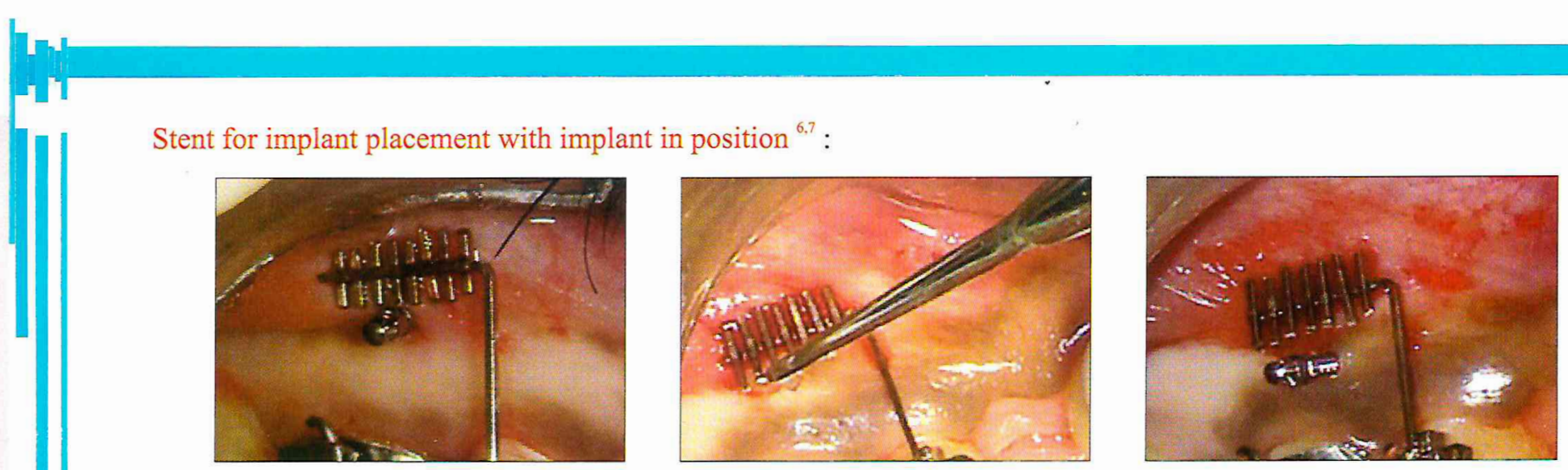

Radiographs to evaluate implant position in inter radicular bone
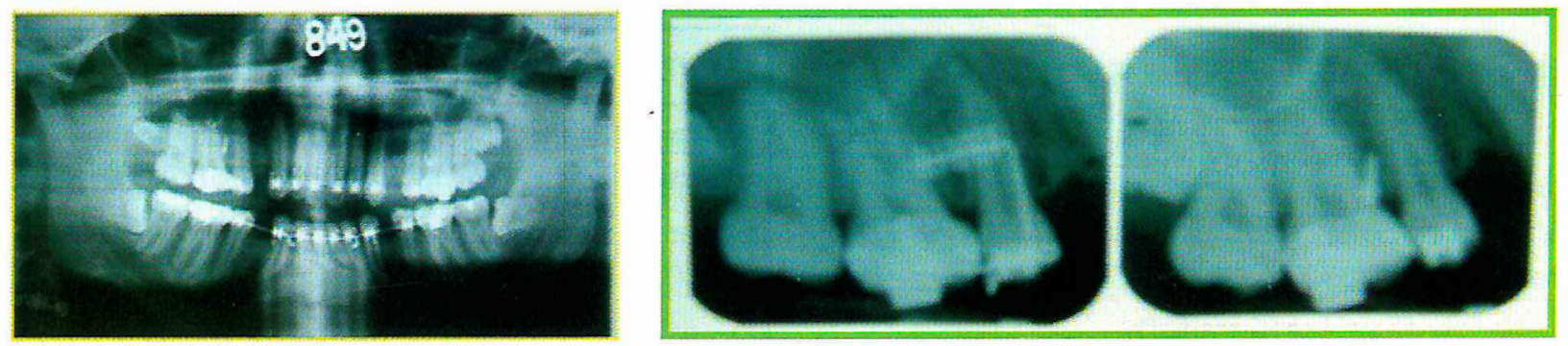

Case - 1 :
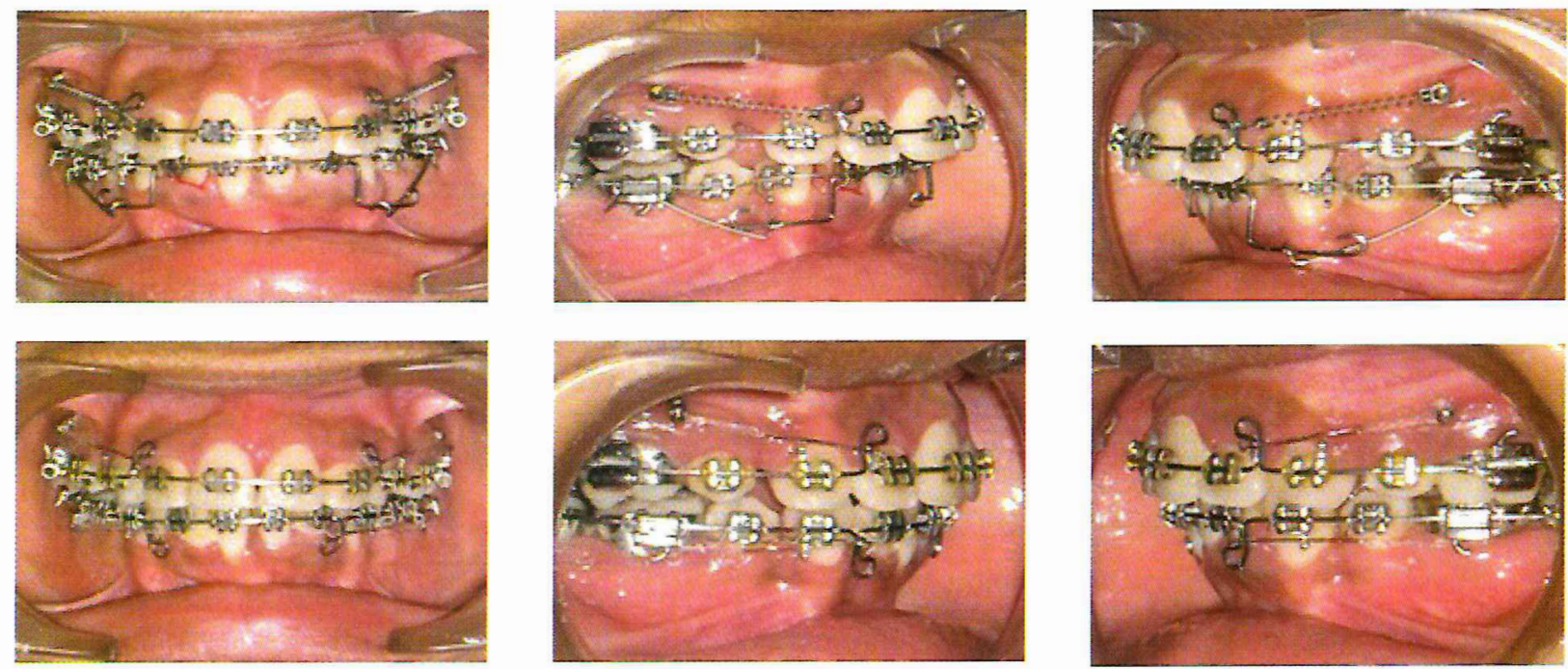

Implants used for retraction of anteriors (Absolute anchorage)

Case - 2 :
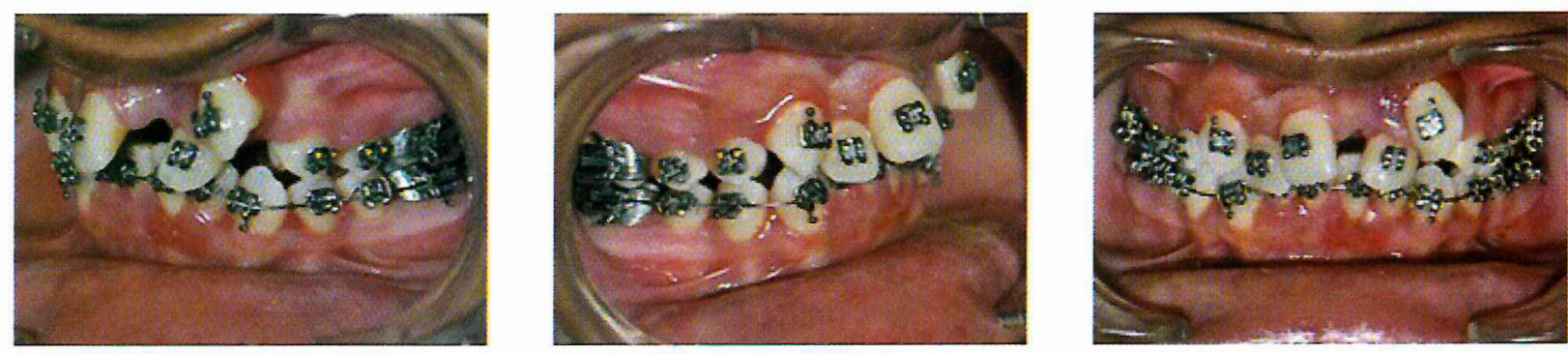

Role Of Implants In Orthodontics 13 Vol:4 Issue: 2 CODS - Sep 2012 

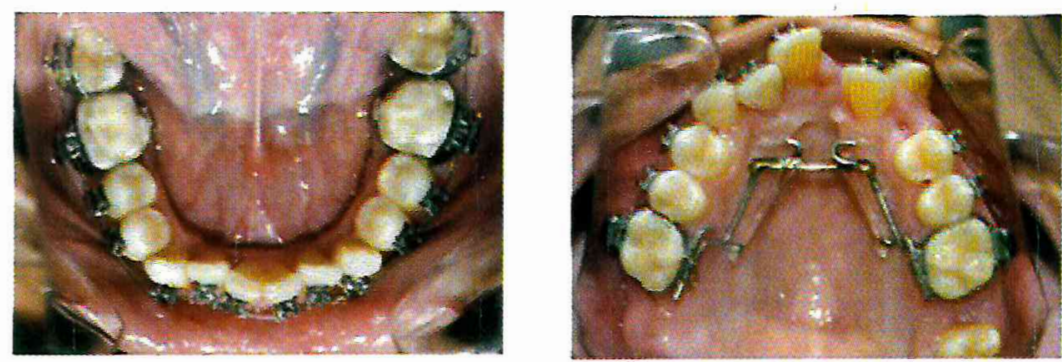

Implants used for distilization of molars (palatal placed implant).

Case - 3 :
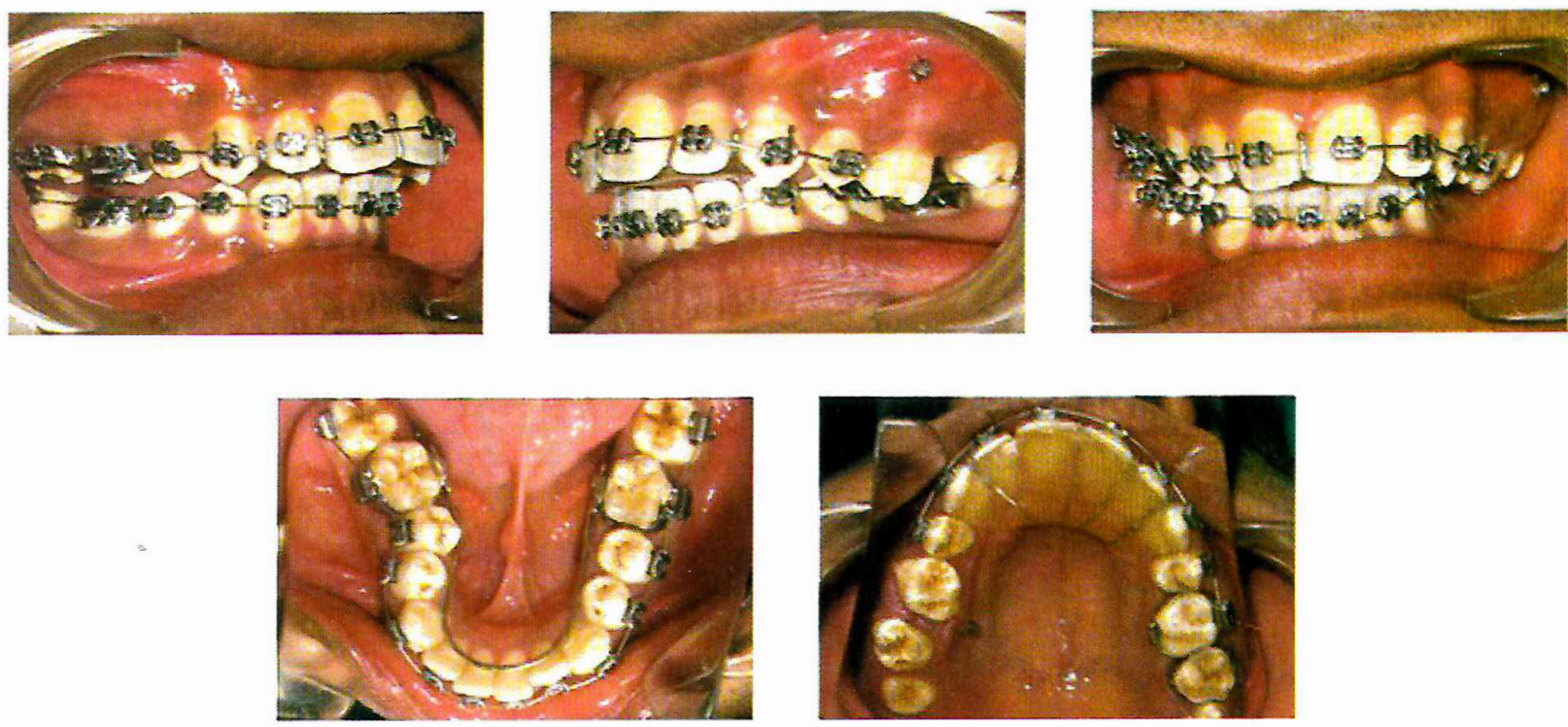

Implants used for intrusion of maxillary molars using buccal and palatal implants

\section{REFERENCES :}

1. Ismail $\mathrm{S}$ et al. The role of implants in orthodontics. Journal of orthodontics vol.29, 239-245, 2002.

2. Ravindra Nanda, Flavo Andews: Temporary anchorage devices in orthodontics :Mosby publication.

3. Jong Suk Lee et al. Application of orthodontic miniimplants. Quintessence publishing 2007.

4. Kanomi R. Mini-implant for orthodontic anchorage. J Clin Orthod 1997; 31: 763-67.

5. Deguchi T, Takano-Yamamoto $\mathrm{T}$, Kanomi R, Hartsfield JK, Roberts WE, Garetto LP. The use of small titanium screws for orthodontic anchorage. $\mathrm{J}$ Dent Res 2003; 82:377-81.
6. Melsen B, Costa A. Immediate loading of implants used for orthodontic anchorage. Clin Orthod Res 2000; 3:23-28.

7. Poggio PM, Incorvati C, Velo S, Carano A. 'Safe zones': a guide for microscrew positioning in the maxillary and mandibular arch. Angle Orthod 2006; 76: 191-97. 